\title{
Impact of COVID- I 9 Pandemic Led Lockdown on the Lifestyle of Adolescents and Young Adults
}

\author{
Shubhajeet Roy', Sunita Tiwari', Shweta Kanchan ${ }^{3}$, Prashant Bajpai ${ }^{4}$ \\ ${ }^{1}$ MBBS, First Professional Year Student, Faculty of Medical Sciences, King George's Medical University, Lucknow, U.P., India. \\ ${ }^{2}$ Head, Department of Physiology, King George's Medical University, Lucknow, U.P., India. \\ ${ }^{3}$ Department of Physiology, King George's Medical University, Lucknow, U.P., India. \\ ${ }^{4}$ Biostatistician and Lead Data Manager, Abbott Healthcare Pvt. Ltd. \\ DOI: https://doi.org/10.24321/2349.2880.202008
}

$\begin{array}{lllllll}\mathbf{I} & \mathbf{N} & \mathbf{F} & \mathbf{O}\end{array}$

\section{Corresponding Author:}

Shubhajeet Roy, Faculty of Medical Sciences, King George's Medical University, Lucknow, Uttar Pradesh, India.

E-mail Id:

shubhajeet5944.19@kgmcindia.edu

Orcid Id:

https://orcid.org/0000-0003-1092-9668

How to cite this article:

Roy S, Tiwari S, Kanchan S, Bajpai P. Impact of COVID-19 Pandemic Led Lockdown on the Lifestyle of Adolescents and Young Adults. Ind J Youth Adol Health 2020; 7(2): 12-15.

Date of Submission: 2020-09-27

Date of Acceptance: 2020-11-27

\section{$\begin{array}{llllllll}\text { A } & \text { B } & \mathbf{S} & \mathbf{T} & \mathbf{R} & \mathbf{A} & \mathbf{C} & \mathbf{T}\end{array}$}

Background: The COVID-19 pandemic led lockdown-an unprecedented event wherein people globally have been hit hard. This lockdown has caused a deep impact on lifestyle-related parameters like sleep pattern, diet pattern, stress level, physical activity level and circadian rhythms.

Objective: This study was designed to study effect of COVID-19 pandemic on lifestyle of young adults and adolescents.

Method: Online survey was conducted in 1065 respondents in the age group of 13 to 25 years.

Result: Questionnaire-based survey showed mean sleep duration changing from 6.85 hours to 8.17 hours, average screen time increased to 5.12 hours from 3.5 hours, $51.9 \%$ subjects experienced higher stress levels, $76.4 \%$ subjects experienced more food intake and $38.6 \%$ subjects had decreased levels of physical activity as per self-monitoring.

Conclusion: These changes might have long lasting effects on their physical, mental and social health and need counteractive measures to help young people lead a healthy lifestyle during the epidemic and beyond.

Keywords: COVID-19, Pandemic, Lockdown, Youth, Life Style

\section{Introduction}

COVID-19 pandemic began from Wuhan, China and spread like wildfire across the globe. Total lockdown, consequent to it, taken for preventing spread of COVID-19, resulted in changes in daily life schedule, daily physical activity level, changes in daily life schedule, daily physical activity level, mental activity level, food intake level, sleep duration. Restricted physical activity, unlimited screen time and circadian rhythm disturbance coupled with minimal exposure to sunlight-the primary determinant of our circadian rhythm ${ }^{1}$ and erratic food patterns, have serious repercussions on our health and wellbeing. Even after lockdown is lifted, life will not remain the same as seen in studies. ${ }^{2}$ The present study is an attempt to find out the effect of this pandemic led lockdown on the lifestyle of younger population.

\section{Materials and Methods}

The study was a questionnaire-based survey, created using Google Forms, which was circulated by the investigators via various social media apps like - Whats App, Facebook, LinkedIn and Instagram, during the first 2 weeks of August, 2020. Ethical clearance was obtained before the study from Institutional Ethics Committee for Human Research, King George's Medical University, Lucknow, India. The questionnaire was based on the Fantastic Lifestyle 
Questionnaire, ${ }^{3}$ which was served as an online link. The snowball sampling was used to circulate it widely across India. Indian subjects literate enough to understand the questionnaire and in the age group 13 years to 25 years were included in the study. Although, subjects suffering from any chronic disease like diabetes, hypertension, asthma, mental illness and other systemic diseases were not included in this study. The online link opened with the question of Informed Consent. The questionnaire included questions on sociodemographic parameters followed by questions related to sleep, screen time, stress level (since our study was not restricted to studying stress only, but was aimed at studying overall lifestyle changes, no separate stress questionnaire was used, rather the part of the same Fantastic Lifestyle Questionnaire3 devoted to stress was employed here), food intake and physical activity levels. Based on the responses, they were statistically analysed using descriptive analysis tests, which involved frequency tabulation, to find the impact of this lockdown on the lifestyle of adolescents and young adults. All statistical analyses were made using SPSS VERSION 23 software (this is a software package used for interactive or batched statistical analysis; SPSS stands for Statistical Package for the Social Sciences; SPSS Statistics supports a top-down, hypothesis testing approach to the data, whereas SPSS Modeller exposes patterns in data through a bottomup, hypothesis generation approach). All procedures were followed according to the ethical standards of human experimentation and the Helsinki declaration (rev. 2013).

\section{Result}

A total of 1065 subjects were enrolled and they gave their consent to participate in the survey.

The mean \pm SD of age was reported as $19.918 \pm 3.5388$ years. $19 \%$ subjects were from rural background, whereas $81 \%$ were from urban background.3.098\% subjects were present in junior classes, i.e. below class $\mathrm{X}, 8.92 \%$ were $\mathrm{X}$ pass, $13.521 \%$ were XII pass, $65.44 \%$ were undergraduates, $7.136 \%$ were postgraduates and $1.784 \%$ had other educational qualifications.

\section{Comparative Study of Average Duration of Sleep Before and After Lockdown}

Table I.Changes in sleep duration before lockdown and during lockdown

\begin{tabular}{|c|c|c|c|c|}
\hline \multirow[b]{2}{*}{$\begin{array}{l}\text { Average } \\
\text { No. of } \\
\text { Hours of } \\
\text { Sleep }\end{array}$} & \multicolumn{2}{|c|}{ Before Lockdown } & \multicolumn{2}{|c|}{ During Lockdown } \\
\hline & $\begin{array}{c}\text { Number } \\
\text { of } \\
\text { subjects } \\
(n=1065)\end{array}$ & $\begin{array}{c}\% \text { of } \\
\text { subjects }\end{array}$ & $\begin{array}{c}\text { Number } \\
\text { of } \\
\text { subjects } \\
(n=1065)\end{array}$ & $\begin{array}{c}\% \text { of su } \\
\text { bjects }\end{array}$ \\
\hline $\begin{array}{c}\text { 4-6 Hours } \\
\text { / day }\end{array}$ & 241 & $22.6 \%$ & 83 & $7.8 \%$ \\
\hline $\begin{array}{l}\text { 6-8 Hours } \\
\text { / day }\end{array}$ & 672 & $63.1 \%$ & 420 & $39.4 \%$ \\
\hline
\end{tabular}

\begin{tabular}{|c|c|c|c|c|}
\hline $\begin{array}{c}8-10 \\
\text { Hours / } \\
\text { day }\end{array}$ & 140 & $13.1 \%$ & 463 & $43.5 \%$ \\
\hline $\begin{array}{c}>10 \text { Hours } \\
\text { /day }\end{array}$ & 12 & $1.1 \%$ & 99 & $9.3 \%$ \\
\hline
\end{tabular}

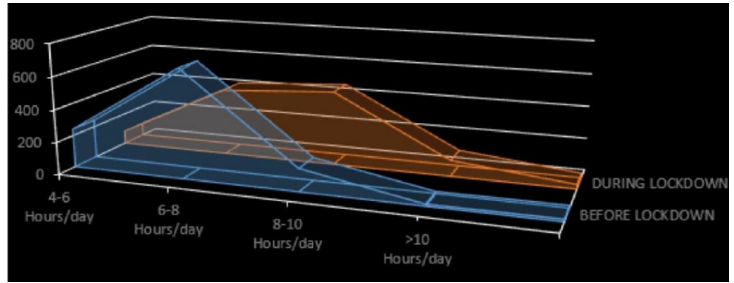

Figure I.Changes in sleep duration before lockdown and during lockdown

Average sleep duration changed from 6.858 hours before lockdown to 8.179 hours during lockdown. Table 1 , shows number and percentage of subjects on the basis of average number of hours of sleep, before and during lockdown. Even it is evident from Figure 1 that the peak of the 2 nd curve (in orange) has shifted rightwards (towards higher extremity).

\section{Average Screen Time during Lockdown}

Table 2.Average screen time during lockdown

\begin{tabular}{|c|c|c|}
\hline $\begin{array}{c}\text { Average Screen Time } \\
\text { During Lockdown }\end{array}$ & $\begin{array}{c}\text { Numberof } \\
\text { Subjects }(\mathbf{n}=1065)\end{array}$ & $\begin{array}{c}\text { \% of } \\
\text { Subjects }\end{array}$ \\
\hline$<1$ Hour & 33 & $3.1 \%$ \\
\hline $1-2$ Hours & 177 & $16.6 \%$ \\
\hline $2-5$ Hours & 389 & $36.5 \%$ \\
\hline$>5$ Hours & 466 & $43.8 \%$ \\
\hline
\end{tabular}

The average screen time has increased during lockdown, with average screen time being 5.12985 hours, which is very high when seen in Indian scenario. Table 2, shows number and percentage of subjects on the basis of average screen time during lockdown. Pre lockdown data of Screen time in India is an average of 3.5 hours. ${ }^{4}$

\section{Impact on Stress Level}

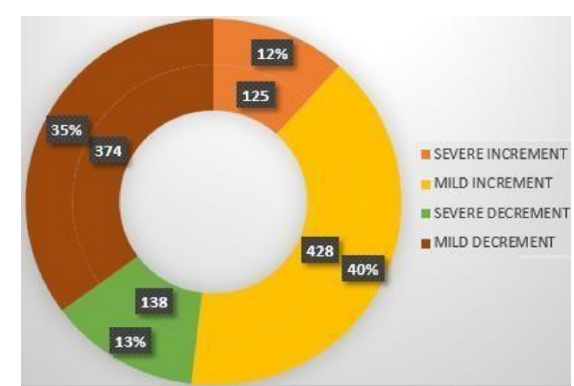

Figure 2.Changes In Stress Level Compared To Pre Lockdown Levels $(n=1065)$

(Labels represent frequency in inner circle and percentage in outer circle) 
$48.1 \%$ subjects responded by saying that there had been a decrease in their stress level. But a majority of $51.9 \%$ said that they had experienced an increase in their stress levels during this time (Figure 2).

\section{Impact on Quantity of Food Intake}

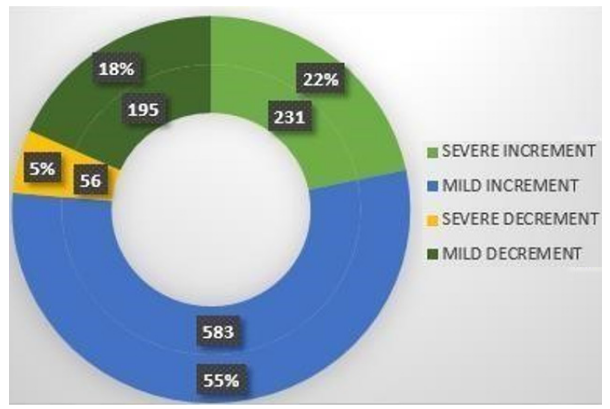

Figure 3. Changes in food intake compared to prelockdown conditions. $(n=1065)$

(Labels represent frequency in inner circle and percentage in outer circle)

$23.6 \%$ subjects recorded a decrease in the quantity of their food intake, whereas a vast majority of $76.4 \%$ subjects voted in the contrary (Figure 3).

\section{Level of Physical Activity during Lockdown}

Table 3.Level of physical activity, as compared to pre lockdown conditions. (As per self- monitoring)

\begin{tabular}{|c|c|c|}
\hline $\begin{array}{c}\text { Level of physical activity } \\
\text { during lockdown }\end{array}$ & $\begin{array}{c}\text { Number } \\
\text { of subjects } \\
(\mathbf{n}=\mathbf{1 0 6 5})\end{array}$ & $\begin{array}{c}\text { Percentage } \\
\text { of Subjects }\end{array}$ \\
\hline Less than before & 411 & $38.6 \%$ \\
\hline More than before & 260 & $24.4 \%$ \\
\hline Same as before & 394 & $37.0 \%$ \\
\hline
\end{tabular}

Table 3, clearly shows that the level of physical activity has decreased for greater number of subjects (38.6\%) or it has remained the same, as seen in $37 \%$ subjects.

We also asked our subjects whether they have tried anything creative or have learnt anything new during this time, to which $79.3 \%$ replied in the affirmative.

\section{Discussion}

Results of the present study show a clear increment in the sleep duration in majority of the subjects (Figure 1). This might be simply due to the fact that there is increased availability of leisure time. Although the quality of this extra duration of sleep remains to be seen. The increase in screen time (Table 2) as observed in the study might be due to the rapid surge in online classes by educational institutes, in an effort to cope up with the back-log of classes due to this lockdown. Moreover, increased free time for the youth has led to the increased time that they are spending over social media apps and also increased rate of binge watching. 3 weeks after the COVID-19 outbreak led lockdown, smartphone usage time/user increased by average 13\%/user (weekly) and average 12\%/user (daily). Daily time spent per user on video streaming platforms (VOD) increased in parallel to smartphone usage. New apps and websites also clocked growth via smartphone. ${ }^{5}$

The increase in stress level (Figure 2), which happened with the majority can be associated to many causes like: first and foremost threat of infection from the dreadful virus and the overload of negative news from various kinds of media sources which has created a negative ambience all around; also there is the threat of losing their near and dear ones. Secondly, unemployment and loss of family income owing to the lockdown can also be a major cause of worry and stress. Also, for the educated youth, the big question mark over their future prospects and opportunities and lack of infrastructural advantages can also be a major stressor. Most reviewed studies reported negative psychological effects including posttraumatic stress symptoms, confusion, and anger. Stressors included infection fears, frustration, boredom, inadequate supplies, inadequate information, financial loss, and stigma. Some researchers have suggested long-lasting effects. ${ }^{6}$ Our results were similar to those found by Stanton et al: According to DASS 21 Scale, $12.7 \%$ subjects scored severe or extremely severe and $25.5 \%$ scored mild or moderate for Depression, $7.9 \%$ subjects scored severe or extremely severe and $13.3 \%$ scored mild or moderate for Anxiety, and $10.0 \%$ scored severe or extremely severe and $17.7 \%$ scored mild or moderate for Stress. Also, as severity of depression increased, composite health behaviour change score worsened as well. Those scoring normal for depression had a small negative change of -0.42 and those scoring extremely severe had it almost 3 times greater: -1.45.7 Although, in Italian subjects mean scores for Depression, Anxiety and Stress on the same scale was 5.34, 2.89 and 7.43 respectively, ${ }^{8}$ as compared to $4.6,2.2$ and 5.2 respectively in Australian subjects. ${ }^{7}$

A deeper analysis, also leads to revelation of the fact that during this time due to the homeostatic, neuroendocrine, circadian rhythms and stress imbalances, there might be increased release of the hormone Ghrelin ${ }^{9}$ and Ghrelin induces hunger greatly. ${ }^{10}$

The matter of concern is the fact that the coupled increase in food intake (Figure 3 ) and decrease in physical activity levels (Table 3) can have debilitating effects on the overall health of a being - starting from weight gain and obesity and finally leading to severe complications like diabetes, cardiovascular diseases and other serious conditions. ${ }^{11}$ For adolescents afflicted with excess adiposity, it is very important to identify the adverse side effects of this pandemic led lockdown on decreasing of their weight control methods. The untoward 
lockdown effects, although depending on the duration, are very much likely to have a lasting impact on an adolescent's adult adiposity level. ${ }^{12}$ Increased screen- time (Table 2) accompanied with increased stress levels (Figure 2) and decreased levels of physical activity (Table 3), may have their due repercussions on an adolescent's ophthalmic health with subsequent changes in retinal microvascular structure $^{13}$ also, leading to a string of other psychological, physical and cognitive disorders viz. obesity, insomnia and other sleep related problems, depression and anxiety, and many other lifestyle disorders, having lasting impact on an adolescent's adult health and lifestyle. ${ }^{14}$

The study could have been made more elaborate with a larger sample size and a longer follow up for residual side effects of lock down.

\section{Conclusion}

The above study showed changes in the various lifestyle indices in younger population owing to the COVID-19 pandemic led lockdown. The increased screen time and habits like binge watching could be countered by an encouragement of co-curricular activities in the adolescent and young adults. Indoor physical activity and outdoor activity with due precautions should be encouraged by parents and educational institutes as a part of their online education. The course of the pandemic is uncertain, and may last long. Young generation should maintain a fixed sleep-wake schedule, healthy eating habits and some degree of exercise regime while following the safety norms to prevent the spread of contagion, only then can the youth emerge victorious and expand their horizons even under the restrictions imposed by the corona virus.

\section{Acknowledgement}

In the conduction of this study, we were helped in a number of stages by a few people we would like to mention. In the data collection process, we were helped a lot, by three undergraduate students, namely: Ms Nikita Singh, Mr Siddhant Aggarwal and Ms Devanshi Katiyar.

\section{Conflict of Interest: None \\ References}

1. Roenneberg $\mathrm{T}$, Kuehnle $\mathrm{T}$, Juda M, Kantermann $\mathrm{T}$, Allebrandt K, Gordijn M, Merrow M. Epidemiology of the human circadian clock. Sleep Medicine Reviews 2007; 11(6): 429-438.

2. Zarrinpar A, Chaix A, S Panda. Daily Eating Patterns and Their Impact on Health and Disease Published: December 16, 2015. DOI PlumX Metrics.

3. Añez CR, Reis RS, Petroski EL. Brazilian version of a lifestyle questionnaire: translation and validation for young adults. Arq Bras Cardiol 2008; 91(2): 92-98.

4. Han J. India Time Spent with Media 2019. emarketer
May 30,2019.

5. https://www.emarketer.com/content/india-time-spentwith-media-2019 Acessed on: July 3, 2020.

6. Shakir A, Shaikh S, Aggarwal A. Media. Motilal Oswal: Sector Update. 2020 April 16.

7. Brooks SK, Webster RK, Smith LE, Woodland L, Wessely S, Greenberg N, Rubin GJ. The psychological impact of quarantine and how to reduce it: rapid review of the evidence. The Lancet 2020 Feb 26.

8. Stanton R, To QG, Khalesi S, Williams SL, Alley SJ, Thwaite TL, Fenning AS, Vandelanotte C. Depression, Anxiety and Stress during COVID-19:

9. Associations with Changes in Physical Activity, Sleep, Tobacco and Alcohol Use in Australian Adults. International Journal of Environmental Research and Public Health 2020; 17(11): 4065.

10. Mazza C, Ricci E, Biondi S, Colasanti M, Ferracuti S, Napoli C, Roma P. A nationwide survey of psychological distress among italian people during the COVID-19 pandemic: Immediate psychological responses and associated factors. Int J Environ Res Public Health 2020; 17: 3165.

11. Asakawa A, Inui A, Kaga T, Yuzuriha $H$, Nagata T, Fujimiya M, Katsuura G, Makino S, Fujino MA, Kasuga M. A role of ghrelin in neuroendocrine and behavioral responses to stress in mice. Neuroendocrinology 2001; 74(3): 143-147.

12. Higgins SC, Gueorguiev M, Korbonits M. Ghrelin, the peripheral hunger hormone. Annals of Medicine. 2007; 39(2): 116-136.

13. Astrup A. Healthy lifestyles in Europe: prevention of obesity and type II diabetes by diet and physical activity. Public Health Nutrition 2001; 4(2b): 499-515.

14. Pietrobelli A, Pecoraro L, Ferruzzi A, Heo M, Faith M, Zoller T, Antoniazzi F, Piacentini G, Fearnbach SN, Heymsfield SB. Effects of COVID 19 lockdown on lifestyle behaviors in children with obesity living in Verona, Italy: a longitudinal study. Obesity 2020 Apr 30.

15. Gopinath B, Baur LA, Wang JJ, Hardy LL, Teber E, Kifley A, Wong TY, Mitchell P. Influence of physical activity and screen time on the retinal microvasculature in young children. Arteriosclerosis, Thrombosis, and Vascular Biology 2011; 31(5): 1233-9.

16. Domingues Montanari S. Clinical and psychological effects of excessive screen time on children. Journal of paediatrics and child health 2017; 53(4): 333-338. 